BMJ Open Sport \& Exercise Medicine

\title{
Knowledge of the physical activity guidelines and factors associated with physical activity participation among adults in Harar town, eastern Ethiopia
}

\author{
Chalchisa Abdeta, ${ }^{1}$ Berhanu Seyoum, ${ }^{2}$ Zelalem Teklemariam ${ }^{2}$
}

\begin{abstract}
To cite: Abdeta C, Seyoum B, Teklemariam Z. Knowledge of the physical activity guidelines and factors associated with physical activity participation among adults in Harar town eastern Ethiopia. BMJ Open Sport \& Exercise Medicine 2019;5:e000463. doi:10.1136/ bmjsem-2018-000463
\end{abstract}

- Additional material is published online only. To view please visit the journal online (http://dx.doi.org/10.1136/ bmjsem-2018-000463)

Accepted 24 December 2018

\section{Check for updates}

(c) Author(s) (or their employer(s)) 2019. Re-use permitted under CC BY-NC. No commercial re-use. See rights and permissions. Published by BMJ.

'Department of Physiotherapy, Hiwot Fana Specialized University Hospital, Haramaya University, Harar, Ethiopia ${ }^{2}$ Department of Medical Laboratory Technology, College of Health and Medical Sciences, Haramaya University, Harar, Ethiopia

Correspondence to

Chalchisa Abdeta; caaliphysio@ gmail.com

\section{ABSTRACT}

Objectives We assessed knowledge of the physical activity guidelines and factors associated with physical activity participation among adults in Harar town, eastern Ethiopia.

Design A cross-sectional study of 590 adults in Harar town with face-to-face interview.

Results Only $27 \%$ of participants had good knowledge of the physical activity guidelines. The extent of physical activity participation was $54 \%$ (95\% Cl $50.0 \%$ to $58.4 \%)$. Male participants (adjusted OR (AOR) 2.14; 95\% Cl 1.49 to 3.07), educational status of college diploma and above (A0R 2.06; 95\% $\mathrm{Cl} 1.09$ to 3.89), sitting less than 2 hours per day (AOR 1.82; 95\% Cl: $1.17 \%$ to $2.83 \%$ ) and good knowledge of physical activity (AOR 3.03; $95 \% \mathrm{Cl} 1.98$ to 4.64) were associated with physical activity participation. Conclusions There is limited knowledge of physical activity guideline in the study area.

\section{BACKGROUND}

The WHO recommends that adults achieve a minimum of 150 min moderate or $75 \mathrm{~min}$ vigorous intensity aerobic activity per week. Adults who do not succeed this guideline are considered as physically inactive. ${ }^{12}$ Evidence indicated that physical inactivity is become the major problem of world's population including Ethiopia. ${ }^{3}$ Study showed that physical inactivity contributed $5.2 \%$ of all deaths in Ethiopia by 2012. ${ }^{4}$

The knowledge of physical activity guidelines is limited in various countries-there is poor knowledge of physical activity in the UK $(18 \%)$, England $(15 \%)$ and India $(9.3 \%) .^{5-7}$ Another study conducted in UK revealed that almost half $(53 \%)$ of adults had good knowledge of physical activity guide. ${ }^{8}$ However, there were no available data to know how many adults have a good knowledge of physical activity minimum requirements.

On the other hand, the magnitude of physical activity participation was reported from China (43.8\%), Malaysia (56.3\%), Nigeria $(68.6 \%)$ and Ethiopia $(81.1 \%) \cdot{ }^{9-11}$ Evidence

\section{What are the new findings?}

Knowledge of physical activity guideline is very low in the study area.

- Physical activity participation was largely below the guideline level.

- Factors such as sex, educational status, sitting time and knowledge of physical activity guideline were linked with physical activity participation.

- Having a good knowledge of physical activity can boost level of physical activity participation.

shown that different factors were associated with attaining physical activity guideline. For instance, sociodemographic factor (sex, age, educational status, occupation and income) and other factors like knowledge of physical activity guideline, satisfaction with current level of physical activity, future intentions to engage in physical activity and sitting time in day were associated with physical activity participation. ${ }^{5-29}$ There has been limited study on knowledge of physical activity guideline and its participation in Ethiopia. Therefore, this study had three aims: (1) to examine knowledge of physical activity guideline, (2) to determine level of physical activity participation and (3) to identify factors associated with physical activity participation among adults in Harar town, eastern Ethiopia.

\section{METHODS}

\section{Study protocol}

This cross-sectional study was conducted on April 2016 among randomly selected 590 adults in Harar town, eastern Ethiopia. The sample size was determined using Epi Info V.7.0 of StatCalc programme. Then, data was obtained from previous study conducted in Nigeria to run this programme. This was assumed as similar setting with the study area. Accordingly, $73.6 \%$ of physical activity proportion among low income and $60.0 \%$ among high income were taken with adjusted 
OR (AOR) of $0.54 .{ }^{11}$ Assumptions of $90 \%$ power, $95 \%$ CI and 1:1 ratio of the two populations and $10 \%$ of non-response rate were used during this calculation. Lastly, the required sample size become 590 .

Study participants were selected using multistage sampling techniques. Initially, 6 kebeles were selected from the total 19 kebeles using lottery method. The sample size was allocated based on the size of adult populations in selected area. Then, households were selected from each selected kebeles using systematic random sampling technique. Lastly, maximum of two adults were interviewed in a single household to maintain randomness. Lottery method was used if there were more than two adults in a single household.

\section{Data collection}

A face-to-face interview was made to collect the data. Eight data collectors were recruited those have Diploma in Nursing. Similarly, two supervisors were also assigned those have Bachelor degree in Health officer. Two days training was given on data collection methods and tools for both data collectors and supervisors. Global physical activity questionnaire (GPAQ) V.2.0 was used to collect the data. At the same time, GPAQ generic show cards were used to clarify questions related to physical activity practice. ${ }^{30}$ Lastly, participants were asked whether or not they were aware of the existence of the WHO physical activity guideline for adults and how much physical activity those guidelines recommended.

\section{Data quality control}

In this study, data quality was maintained at different stages. Initially, questionnaire was translated into local language by experts to suit the local conditions. To keep consistency, it was translated back into English language. Then, data collectors and supervisors were trained. Afterwards, questionnaire was pretested on $5 \%$ of the total sample size out of the study area. Progressively, close supervision was made by supervisors throughout the data collection period. Lastly, double data entry was made to avoid possible errors.

\section{Statistical analysis}

Data were entered into EpiData V.3.02. Then, exported and analysed using SPSS V.20. Statistical analysis was performed for descriptive statistics, bivariate and multivariate logistic regression analysis. Binary logistic regression analyses were done to identify factors associated with physical activity practice. During bivariate analysis, variables with $p$ value less than 0.3 were selected for multivariate analysis to control confounding factors and identify significant factors. Statistical significance was considered at $95 \%$ CI with $\mathrm{p}$ value less than 0.05 .

Physical activity practice was measured by metabolic equivalents (METs)-minutes per week. It was calculated by adding the products of corresponding METs value with the number of days and time spent in a typical week for the three domains of physical activity. ${ }^{30}$ Participants scored more than 600 METs-minutes per week were considered as having a good practice of physical activity. Besides, participants were asked whether or not aware for the WHO physical activity guideline for adults.

\section{RESULTS}

\section{Study participants}

A total of 562 adults were included in this study with the response rate of $95.3 \%$. Participants mean age was 32.0 years with $( \pm 12.2)$ SD. The majority of participants were females $(56.4 \%), 18-30$ years old $(61.0 \%)$, married $(62.6 \%)$, primary and secondary school level $(37.5 \%)$, privately employed (48.9\%), earned from 1000 to 3000 Ethiopian Birr (ETB) (41.1\%), satisfied with current physical activity level $(80.2 \%)$, had intentions to engage in physical activity in a near future $(78.5 \%)$ and sit more than 2 hours in a day (77.8\%) (table 1).

\section{Knowledge of physical activity guideline and its level of participation}

Among the study participants, only $27 \%$ of adults had good knowledge of physical activity guideline (table 1 ). The magnitude of physical activity participation was $54 \%$, higher among the study participants of males $(52.1 \%)$, age group from 18 to 30 years $(61.0 \%)$, educational status of primary and secondary school $(38.4 \%)$, sitting greater than 2 hours per day (72.8\%) and poor knowledge of physical activity guideline $(62.6 \%)$ than others (table 2 ).

\section{Factors associated with physical activity participation}

Variables such as sex, age, educational status, sitting time and knowledge of physical activity guideline were showed an association with physical activity participation in bivariate analysis. However, variable age was not significantly associated with physical activity participation in multivariate analysis. Male participants were more than two times more likely to practice physical activity than females (AOR 2.14; 95\% CI 1.49 to 3.07). Likewise, adults with educational status of college diploma and above more than two times more likely to take part in physical activity participation than those not read and write (AOR 2.06; 95\% CI 1.09 to 3.89). Participants with sitting less than 2 hours per day were nearly two times more likely to engage in physical activity participation than their counterparts (AOR 1.82; $95 \%$ CI $1.17 \%$ to $2.83 \%$ ). Moreover, adults those had good knowledge of physical activity were three times more likely to practice physical activity than those do not have it (AOR 3.03; 95\% CI 1.98 to 4.64) (table 2).

Additional supplementary material can be availed at online supplementary file 1 .

\section{DISCUSSION}

\section{Knowledge of the guidelines}

The knowledge of the physical activity guidelines among Ethiopian adults was very low. This result was comparable with study finding of $32 \%$ from Nigeria. ${ }^{11}$ However, it was lower than another study report of $63 \%$ in Nigeria ${ }^{17}$ and of $66 \%$ in Brazil. ${ }^{18}$ Unlikely, higher results of $9 \%$ from 
Table 1 Characteristics of the study participants among adults in Harar town, eastern Ethiopia, April 2016 ( $\mathrm{n=562}$ )

\begin{tabular}{|c|c|c|}
\hline Variable & Characteristics & Frequency (\%) \\
\hline \multirow[t]{2}{*}{ Sex } & Male & $245(43.6 \%)$ \\
\hline & Female & $317(56.4 \%)$ \\
\hline \multirow[t]{4}{*}{ Age groups (years) } & 18-30 & $343(61.0 \%)$ \\
\hline & $31-40$ & $109(19.4 \%)$ \\
\hline & $41-50$ & $43(7.7 \%)$ \\
\hline & $51-64$ & $67(11.9 \%)$ \\
\hline \multirow[t]{5}{*}{ Marital status } & Single & $186(33.1 \%)$ \\
\hline & Married & $352(62.6 \%)$ \\
\hline & Divorced & $9(1.6 \%)$ \\
\hline & Separated & $13(2.3 \%)$ \\
\hline & Windowed & $2(0.4 \%)$ \\
\hline \multirow[t]{4}{*}{ Educational status } & Not write and read & $61(10.9 \%)$ \\
\hline & Write and read only & $129(23.0 \%)$ \\
\hline & Primary school and above & $211(37.5 \%)$ \\
\hline & College diploma and above & $161(28.6 \%)$ \\
\hline \multirow[t]{4}{*}{ Occupation } & Unemployed & $102(18.1 \%)$ \\
\hline & Government employed & $161(28.6 \%)$ \\
\hline & Private employed & $275(48.9 \%)$ \\
\hline & NGO employed & $24(4.4 \%)$ \\
\hline \multirow[t]{4}{*}{ Monthly income (ETB) } & $<1000$ & $188(33.4 \%)$ \\
\hline & $1000-3000$ & $231(41.1 \%)$ \\
\hline & $3001-5000$ & $65(11.6 \%)$ \\
\hline & $>5000$ & $78(13.9 \%)$ \\
\hline \multirow[t]{2}{*}{ Satisfaction with current level of PA } & Not satisfied & $111(19.8 \%)$ \\
\hline & Satisfied & $451(80.2 \%)$ \\
\hline \multirow[t]{2}{*}{ Intentions to participate in PA in a near future } & No intentions & $121(21.5 \%)$ \\
\hline & Have intentions & $441(78.5 \%)$ \\
\hline \multirow[t]{2}{*}{ Sitting time in a day } & $\leq 2$ hours & $125(22.2 \%)$ \\
\hline & $>2$ hours & $437(77.8 \%)$ \\
\hline \multirow[t]{2}{*}{ Knowledge of PA guideline } & Poor & 409 (72.8\%) \\
\hline & Good & $153(27.2 \%)$ \\
\hline
\end{tabular}

ETB, Ethiopian Birr; NGO, non-governmental organisation; PA, physical activity.

India ${ }^{8}$ and $15 \%$ from England were reported. ${ }^{19}$ The possible reason for this variation might be as a result of unequal information disseminations about physical activity across the countries. In Ethiopia, information is limited on spreading of physical activity guideline.

Our study also revealed that the level of physical activity participation among adults was low-only about half $(54 \%)$ of the study participants attained the recommended level. It was similar with study carried out in Malaysia $(56 \%) .{ }^{9}$ The similarity might be due to a rise of physical inactivity across the countries. ${ }^{19}$ However, it was higher than $39.9 \%$ of study findings from Pakistan, ${ }^{13}$ $40.0 \%$ from Nigeria ${ }^{20}$ and $45.6 \%$ from India. ${ }^{21}$ But, it was lower than study results of $86 \%$ in Kenya, ${ }^{22} 81 \%$ in Nigeria, ${ }^{19} 81 \%$ in Mexico ${ }^{18}$ and $68 \%$ in Poland. ${ }^{12}$ The reason might be due to setting, study period and lifestyle differences. 101923

\section{What influences people to participate in physical activity?}

The participation of physical activity among adults can be affected by different factors. This study identified that male adults were more likely to practice physical activity than females. Similar findings were reported from study conducted in Brazil, ${ }^{24}$ Malaysia, ${ }^{10}$ China, ${ }^{9}$ Kingdom of Saudi Arabia, ${ }^{15}$ India, ${ }^{22}$ South Africa ${ }^{25}$ and Nigeria. ${ }^{20}$ The reason might be due to male participations in heavy work that makes them to be active as compared with females. ${ }^{10152024}$ Likewise, participants with educational status of college diploma and above were more likely to practice physical activity than those not read and write. 
Table 2 Factors associated with physical activity participation among adults in Harar town, eastern Ethiopia, April 2016 $(n=562)$

\begin{tabular}{|c|c|c|c|c|}
\hline \multirow[b]{2}{*}{ Characteristics } & \multicolumn{2}{|c|}{ Physical activity participation } & \multirow{2}{*}{$\begin{array}{l}\text { Adjusted OR } \\
(95 \% \mathrm{Cl})\end{array}$} & \multirow[b]{2}{*}{$P$ value } \\
\hline & Active & Inactive & & \\
\hline \multicolumn{5}{|l|}{ Sex } \\
\hline Male & $159(52.1 \%)$ & $86(33.5 \%)$ & 2.14 (1.49 to 3.07$)$ & $0.000^{*}$ \\
\hline Female & $146(47.9 \%)$ & $171(66.5 \%)$ & 1 & \\
\hline \multicolumn{5}{|l|}{ Age group (years) } \\
\hline $18-30$ & $186(61.0 \%)$ & $157(61.1 \%)$ & 1.17 (0.67 to 2.05$)$ & 0.573 \\
\hline $31-40$ & $69(22.6 \%)$ & $40(15.6 \%)$ & 1.83 (0.95 to 3.55$)$ & 0.071 \\
\hline $41-50$ & $18(5.9 \%)$ & $25(9.7 \%)$ & 0.79 (0.36 to 1.78$)$ & 0.579 \\
\hline $51-64$ & $32(10.5 \%)$ & $35(13.6 \%)$ & 1 & \\
\hline \multicolumn{5}{|l|}{ Educational status } \\
\hline Not write and read & $25(8.2 \%)$ & $36(14.0 \%)$ & 1 & \\
\hline Write and read only & $67(22.0 \%)$ & $62(24.1 \%)$ & 1.56 (0.81 to 2.99$)$ & 0.184 \\
\hline Primary school and above & $117(38.4 \%)$ & $94(36.6 \%)$ & 1.65 (0.89 to 3.03$)$ & 0.107 \\
\hline College diploma and above & $96(31.5 \%)$ & $65(25.3 \%)$ & 2.06 (1.09 to 3.89 ) & $0.025^{\star}$ \\
\hline \multicolumn{5}{|l|}{ Sitting time in a day } \\
\hline$\leq 2$ hours & $83(27.2 \%)$ & $42(16.3 \%)$ & 1 & $0.008^{*}$ \\
\hline$>2$ hours & $222(72.8 \%)$ & $215(83.7 \%)$ & $1.82(1.17$ to 2.83$)$ & \\
\hline \multicolumn{5}{|c|}{ Knowledge of physical activity guideline } \\
\hline Poor & $191(62.6 \%)$ & $218(84.8 \%)$ & 1 & $0.000^{*}$ \\
\hline Good & $114(37.4 \%)$ & 39 (15.2\%) & 3.03 (1.98 to 4.64$)$ & \\
\hline
\end{tabular}

${ }^{*} \mathrm{P}$ value $<0.05$, statistically significant at $95 \% \mathrm{Cl}$.

This result was similar to study findings in Brazil ${ }^{24}$ and Lebanon. ${ }^{16}$ The similarity might be due to previous experience with physical education course at schools. Participants who sat for fewer than 2 hours per day were more likely to practice physical activity than those sitting more than 2 hours per day. This result was similar with study done in South Africa ${ }^{26}$ and Nigeria. ${ }^{27} 28$ The reason is that participants sitting less can spent more time in active tasks that can assist them for physical activity practice. Adults those had good knowledge of physical activity guideline were more likely to take part in physical activity participation than their counterparts. This finding was comparable with study conducted in India, ${ }^{8}$ Nigeria, ${ }^{21}$ Brazil,${ }^{18}$ England $^{5}$ and China. ${ }^{12}$ The reason might be due to previous exposure to physical activity information.

\section{Strength and limitations of the study}

We used standard tools and analysis, some limitations should be considered as follows. First, this study used self-report method which is not strong as objectively measured study. Second, as this study used cross-sectional study design we cannot speak to any cause-effect relationship. Finally, the study was not compared with study conducted in Ethiopia due limited literatures in the country.

\section{CONCLUSION}

This study revealed poor knowledge and low level of physical activity participation among adults in Harar town. This implies that there is a gap on knowledge of physical activity guideline and its level of participation in this part of Ethiopia. Male sex, higher educational status, less sitting time and superior knowledge of physical activity guideline were all positively associated with physical activity participation. Therefore, raising knowledge of physical activity is critical as a first step towards increasing the level of physical activity participation in the study area.

Acknowledgements The authors acknowledged Ms Melat Meket for her stationary material support, data collectors and supervisors for their cooperation and all the study participants for giving their valuable time to this study.

Contributors CA was conceived and designed the study, analysed the data and interpreted the findings. ZT and BS were participated in the preparation of proposal, analysing the data and final report write up. All authors revised and approved the final content of the manuscript.

Funding The authors have not declared a specific grant for this research from any funding agency in the public, commercial or not-for-profit sectors.

Competing interests None declared.

Patient consent for publication Not required.

Ethics approval Ethical approval was obtained from Institutional Health Research and Ethics Review Committee (IHRERC) of Haramaya University College of Health and Medical Science. Before data collection, written signed consent was obtained from the study participants. An individual was interviewed in a separate place 
to keep privacy. Instead of using the name of participants, code was used on questionnaire to maintain confidentiality.

Provenance and peer review Not commissioned; internally peer reviewed.

Data sharing statement Can be obtained from the corresponding author up on request.

Open access This is an open access article distributed in accordance with the Creative Commons Attribution Non Commercial (CC BY-NC 4.0) license, which permits others to distribute, remix, adapt, build upon this work non-commercially, and license their derivative works on different terms, provided the original work is properly cited, appropriate credit is given, any changes made indicated, and the use is non-commercial. See: http://creativecommons.org/licenses/by-nc/4.0/.

\section{REFERENCES}

1. World Health Organization, 2018. Physical activity fact sheets. Available: http://www.who.int/mediacentre/factsheets/fs385/en/ [Accessed 5 Aug 2018].

2. World Health Organization. Global recommendations on physical activity for health. Geneva, Switzerland: WHO Press, 2010.

3. Kohl HW, Craig CL, Lambert EV, et al. The pandemic of physical inactivity: global action for public health. The Lancet 2012;380:294-305.

4. Lee I-M, Shiroma EJ, Lobelo F, et al. Effect of physical inactivity on major non-communicable diseases worldwide: an analysis of burden of disease and life expectancy. Lancet 2012;380:219-29.

5. Knox EC, Musson H, Adams EJ. Knowledge of physical activity recommendations in adults employed in England: associations with individual and workplace-related predictors. Int J Behav Nutr Phys Act 2015;12:69.

6. Knox ECL, Esliger DW, Biddle SJH, et al. Lack of knowledge of physical activity guidelines: can physical activity promotion campaigns do better?: Table 1. BMJ Open 2013;3:e003633.

7. Hunter RF, Tully MA, Donnelly P, et al. Knowledge of UK physical activity guidelines: implications for better targeted health promotion. Preventive Medicine 2014;65:33-9.

8. Anand T, Tanwar S, Kumar R, et al. Knowledge, attitude, and level of physical activity among medical undergraduate students in Delhi. Indian J Med Sci 2011;65:133.

9. Trinh OTH, Nguyen ND, Dibley MJ, et al. The prevalence and correlates of physical inactivity among adults in Ho Chi Minh City. BMC Public Health 2008;8:204.

10. Ying CY, Kuay LK, Huey TC. Prevalence and factors associated with physical inactivity among Malaysian adults. Southeast Asian J Tropmed Public Health 2014;45.

11. Oyeyemi AL, Oyeyemi AY, Jidda ZA, et al. Prevalence of physical activity among adults in a metropolitan Nigerian city: a crosssectional study. Journal of Epidemiology 2013;23:169-77.

12. SS-C H, GP-S H, Xie YJ. Association between physical activity knowledge and levels of physical activity in Chinese adults with type 2 diabetes. Plos One 2014;9:e115098.

13. Biernat E, Tomaszewski P. Association of socio-economic and demographic factors with physical activity of males and females aged 20-69 years. Ann Agric Environ Med 2015;22:118-23.
14. Ranasinghe CD, Ranasinghe P, Jayawardena R, et al. Physical activity patterns among South-Asian adults: a systematic review. Int $J$ Behav Nutr Phys Act 2013;10:116.

15. Al-Zalabani $\mathrm{AH}, \mathrm{Al}-\mathrm{Hamdan} \mathrm{NA}$, Saeed $\mathrm{AA}$. The prevalence of physical activity and its socioeconomic correlates in Kingdom of Saudi Arabia: a cross-sectional population-based national survey. Journal of Taibah University Medical Sciences 2015;10:e215:208-15.

16. Sibai AM, Costanian C, Tohme R, et al. Physical activity in adults with and without diabetes: from the 'high-risk' approach to the 'population-based' approach of prevention. BMC Public Health 2013;13:1002.

17. Aweto $\mathrm{HA}$, Oligbo CN, Fapojuwo OA, et al. Knowledge, attitude and practice of physiotherapists towards promotion of physically active lifestyles in patient management. BMC Health Services Research 2013;13:21.

18. Ribeiro CP, Milanez H. Knowledge, attitude and practice of women in Campinas, São Paulo, Brazil with respect to physical exercise in pregnancy: a descriptive study. Reprod Health 2011;8:31.

19. Medina C, Janssen I, Campos I, et al. Physical inactivity prevalence and trends among Mexican adults: results from the National Health and Nutrition Survey (ENSANUT) 2006 and 2012. BMC Public Health 2013;13:1063.

20. Aliyu SU, Chiroma AS, Jajere AM. Prevalence of physical inactivity, hypertension, obesity and tobacco smoking: a case of NCDS prevention among adults in Maiduguri, Nigeria. Am J Med Sci 2015;3:39-47.

21. Awotidebe TO, R. A. A, Rasaq WA, et al. Knowledge, attitude and practice of exercise for blood pressure control: a cross-sectional survey. Journal of Exercise Science Physiotherapy 2014;10:1-10.

22. Anjana RM, Pradeepa R, Das AK, et al. Physical activity and inactivity patterns in India - results from the ICMR-INDIAB study (Phase-1) [ICMR-INDIAB-5]. Int J Behav Nutr Phys Act 2014;11:26.

23. Haregu TN, Oti S, Egondi T, et al. Co-occurrence of behavioral risk factors of common non-communicable diseases among urban slum dwellers in Nairobi, Kenya. Glob Health Action 2015;8:28697.

24. Florindo AA, Guimarães VV, Cesar CL, et al. Epidemiology of leisure, transportation, occupational, and household physical activity: prevalence and associated factors. J Phys Act Health 2009;6:625-32.

25. Phaswana-Mafuya N, Peltzer K, Chirinda W, et al. Sociodemographic predictors of multiple non-communicable disease risk factors among older adults in South Africa. Glob Health Action 2013;6:20680.

26. Peltzer K, Phawana-Mafuya N. Physical inactivity and associated factors in older adults in South Africa.. Afr J Phys Health Educ Recreat Dance 2012;18:448-61.

27. Oyeyemi AL, Adeyemi O. Relationship of physical activity to cardiovascular risk factors in an urban population of Nigerian adults. Arch Public Health 2013;71:6.

28. Shehu RA, Abdullahi AA, Adekeye DS. Sedentary lifestyle and wellness in Kaduna state, Nigeria. Ethno Med 2010;4:15-19.

29. Guthold R, Louazani SA, Riley LM, et al. Physical activity in 22 African countries: results from the World Health organization stepwise approach to chronic disease risk factor surveillance. Am J Prev Med 2011;41:52-60.

30. World Health Organization. Global physical activity questionnaire (GPAQ) instrument V2. Geneva, Switzerland: WHO Press, 2008. 